\title{
How can we detect when language emerged?
}

\author{
Ian Tattersall ${ }^{1}$
}

Published online: 1 July 2016

(C) Psychonomic Society, Inc. 2016

\begin{abstract}
Views differ radically as to how deep the roots of language lie in human phylogeny, largely because prior to the development of writing systems, this striking human attribute has to be inferred from indirect proxies preserved in the material record. Here I argue that the most appropriate such archaeological proxies encode the modern human symbolic cognitive system from which language emerges. Throughout the 2.5 million years or more for which an archaeological record has existed, change has been both sporadic and rare - until symbolic objects and behaviors begin to appear, well within the tenure of our highly apomorphic species Homo sapiens. I propose that the biology underwriting our unusual cognitive and linguistic systems was acquired in the major developmental reorganization that gave rise to our anatomically distinctive species around 200,000 years ago in Africa. However, the material record indicates that this new potential lay fallow for around 100,000 years, following which it was released by what was necessarily a behavioral stimulus. By far the best candidate for that stimulus is the spontaneous invention of language, which is plausibly underwritten by a relatively simple mental algorithm, and could readily have spurred symbolic cognitive processes in a feedback process. None of this means that earlier hominid vocal communication systems were not complex, or that extinct hominid species were not highly intelligent. But it does emphasize the qualitative distinctiveness of both modern symbolic cognition and language.
\end{abstract}

Ian Tattersall

iant@amnh.org

1 American Museum of Natural History, New York, NY 10024, USA
Keywords Language evolution · Symbolic cognition · Speech evolution · Origin of Homo sapiens

Modern Homo sapiens possesses no more conspicuous behavioral or cognitive apomorphy than complex structured language. So it is hardly surprising that, over the century and a half since the Sociéte de Linguistique de Paris banned such discussion, scholars should have incessantly debated the issue of when and how humans first acquired this unique attribute. More remarkable is the ongoing extreme polarization of views on the matter, with little sign of convergence. Some linguists and cognitive psychologists (e.g., Pinker \& Bloom, 1990) have seen language as so complex and distinctive as to have demanded long nurturing by natural selection, its roots thus penetrating deep into the human evolutionary past. Others (e.g., Bickerton, 1995) have in vivid contrast insisted that language was both a rapid and a recent acquisition in our lineage. That such diametrically opposed viewpoints have been able to coexist so long in stable equilibrium is mainly due to the fact that language is an intangible that is not preserved directly, so that whether or not any extinct hominid possessed it must necessarily be inferred from proxies of the kind that do persist in the material record. And the problem has been that scientists in different disciplines, and even within the same one, have differed enormously in what they are willing to accept as potential proxies for language.

I am going to argue here that the best such proxy is in fact another intangible: symbolic thought of the uniquely human kind. Other animals can, of course, recognize visual and verbal symbols; and chimpanzees and bonobos can even use symbols additively, to make simple statements. But the additive algorithm is ultimately limiting; and what human beings alone do, as far as we can tell, is to recombine the symbols in their mental vocabularies according to rules, not simply to 
describe their emotional states and the condition of the world around them, but to reimagine and reinvent that world. This symbolic capacity of ours resonates in every realm of our experience, and in combination with the complex ancestral foundation of intuitive intelligence and association-making on which it is superimposed (Fitch, 2010; Vauclair, 1996), it is the fount not only of our imagination and creativity, but of all those other cognitive peculiarities that set us apart from even our closest living relatives in nature.

Most importantly, in the present context, symbolic thought appears to be inextricably linked to our capacity for language, in the sense that it demands mental operations of a virtually identical kind. This is an empirical observation, and independent of anything we may infer about how language evolved. Chomsky (e.g., 2000) has argued strenuously for the view that symbolic thought preceded spoken language in human history; if this is correct, although externalized language remains unimaginable without structured thought, thought itself should indeed be possible without verbal language. However, it is clear that at some point in human prehistory our precursors were not thinking symbolically, and that something must thus have happened to start them doing so. In defense of the intimate linkage between language and thought, I shall argue that spoken language was in fact the key releaser of the new cognitive mode among hominids. In other words, language and symbolic thought arose simultaneously in a feedback operation, each dependent on the other. This perspective gains force from Wolfram Hinzen's (2012, p. 647) recently expressed view, formulated from the standpoint of structural linguistics, that language and thought "are not two independent domains of inquiry."

Still, from the perspective of the material record, there is indeed a significant difference between language and thought. Before the very recent invention of writing systems - which everyone can agree substantially postdated language's emergence-language itself left no direct trace in the material record. In contrast, with the aid of clever hands, the advent of symbolic thought among humans rapidly began to leave an indelible and accelerating impression on the environment. As a result, symbolic thought does have a material record; and I propose that, where we find evidence of symbolic thinking, it is reasonable to conclude that the society to which the thinkers belonged also possessed spoken language.

It is important to note that sheer complexity of behavior is not adequate evidence on its own for robust inference of symbolic manipulation of information. Many earlier hominids were clearly extremely complex in cognition, without showing convincing signs of routine symbolic thinking; and it is deeply misleading to use ourselves as any kind of model for how they perceived and experienced the world. Evidently, it is possible to be very impressively smart and resourceful without being smart in the specifically modern-human manner. Saying this is not to demean any of our extinct precursors; it is merely to point out that each had its own identity and cognitive style, and that none deserves to be dismissed as an (implicitly inferior) variant of ourselves.

The ancestral intuitive mental algorithm was, for example, clearly pushed to extraordinary lengths by Homo neanderthalensis (see, e.g., Radovčić, Sršen, Radovčić, \& Frayer, 2015; Rodríguez-Vidal et al., 2014). But this pushing of the envelope was done in the absence of any clearly compelling evidence that these big-brained hominids habitually processed information in our symbolic fashion (see the discussion in Tattersall, 2012, 2015; and contrast Caron, d'Errico, Del Moral, Santos, \& Zilhão, 2011, with Bar-Yosef \& Bordes, 2010, and Higham et al., 2010). Of course, a large literature suggests that Neanderthals possessed language and much of the cognitive apparatus that goes with it (Dediu \& Levinson, 2013, is representative, and see the references therein); but the archaeological evidence cited in defense of this position typically cites examples of the nonsymbolic complexities of behavior already referred to. In a long and remarkably comprehensive record, there is little to suggest that Neanderthals routinely perceived and reworked the world in their minds in the specific way we do today. What is more, references to such features as the ability to hear sounds in the human speech range (e.g., Martínez et al., 2004) and the Neanderthal possession (Krause et al., 2007) of the human version of the FOXP2 allele - one of hundreds involved in proper speech production in humans - are pretty irrelevant to the question of whether Neanderthals actually had language. On the other side of the ledger, an analysis of the relative volumes of the various regions of Neanderthal and modern human brains (Pearce, Stringer, \& Dunbar, 2013) found significant differences that the authors linked to divergent modes of social cognition in the two species.

The archaeological record begins at some time over about 2.5 million years ago, with the manufacture of the first stone cutting tools. Although the small-brained early hominids who made those simple sharp flakes have often been described as "bipedal apes," the fact that they carefully selected appropriate stones and carried them long distances before knapping them as required (Plummer, 2004) placed them beyond the intellectual purview of any modern ape. But once the dramatic invention of flaking stone had been made, stasis reigned; and a million years passed before a new type of stone tool was invented: the teardrop-shaped "handaxe," the first implement made to a deliberate form. This new tool type was invented well after the appearance of our genus Homo, early members of which had the basics of modern body form, although their brains were considerably smaller than ours. And then, yet another million years elapsed before the next innovation in stone tool-making: the "prepared-core" implement, shaped with numerous blows from a hard or soft hammer until a final strike could detach a more or less finished tool possessing a cutting edge all around its periphery. By this point in human 
evolution, very considerable intellectual acumen was routinely involved in stone tool production; additionally, in the period beginning about 400 thousand years ago, we begin to find other significant innovations, such as the regular domestic use of fire, the construction of shelters, the careful shaping of wooden throwing spears, and the making of compound hafted implements (see the review by Klein, 2009).

These novelties are broadly associated with Homo heidelbergensis, a cosmopolitan hominid with a brain not hugely smaller than ours in average size; but it is significant that, even at this advanced technological stage, we still have few if any material productions that can be regarded unequivocally as the products of symbolic minds. What is more, despite the odd straw in the wind, the same thing can be said not only of the large-brained Neanderthals, who came on the European scene about 200 thousand years ago, but also of the very earliest anatomically modern Homo sapiens. These latter, skeletally more or less indistinguishable from ourselves, first show up at Ethiopian sites in the 200- to 160-thousandyear age range, in association with some notably archaic stone tool kits (Klein, 2009). Thus, for all their anatomical novelty, the first Homo sapiens do not appear to have been behaving significantly differently from, say, Neanderthals. In other words, they were smart; but they were not yet smart in our fashion.

Only about 100 thousand years ago, still in Africa, do we begin to pick up traces of a radical change in Homo sapiens behaviors. Following this point, we find evidence of presumptively symbolic body ornamentation, in the form of colored gastropod shells pierced for stringing, and, significantly, of the first explicitly symbolic objects: 80-thousand-year-old ochre plaques engraved with geometric designs. At around the same time, we find evidence of a complex multistage technology designed to transform the very nature of the tool-making materials themselves. Perhaps most tellingly of all, though, at this point the pace of technological innovation began to accelerate hugely, presaging the neophiliac world in which we live today. From being a rarity, change suddenly became routine. And almost certainly not coincidentally, it was at this point that modern humans rapidly spread out of Africa and took over the world, displacing long-established Eurasian hominids in a way no previous invader had ever managed to do. By 40 thousand years ago, artists in European caves were producing some of the most powerful art ever created, uncontested evidence of the modern sensibility; and then, within a remarkably short lapse of time, human beings were standing on the Moon.

Until about 100 thousand years ago, changes in hominid life had been sporadic and unusual. And then, in the blink of an evolutionary eye, change itself had become the norm. So what had happened? Some (e.g., Klein \& Edgar, 2002) argue that this inflection marked the acquisition by some means of the structurally modern human brain, in an event of biological innovation that had no other anatomical sequelae, and for which we have no independent evidence. But there is a much more plausible alternative. The biological event that gave rise to Homo sapiens as a hugely distinctive anatomical entity, in Africa some 200 thousand years ago, had cascading effects throughout the bony skeleton; and there is no obvious reason why those effects should not have extended to soft-tissue systems, including the brain. Cognitive function need not immediately have been affected; as we have seen, behavioral innovations among hominids have typically been made within the tenure of existing species, and indeed, a strong argument can be made that all innovations - which necessarily arise at random to any potential function - must appear initially in exaptive contexts, rather than in adaptive ones. In other words, a structure must already be there before it can be recruited for any function whatsoever. The ancestors of birds had feathers long before it was discovered that these structures could be used in flight; and ancestral tetrapods had bony limbs millions of years before they emerged from the water. By the same token, it is entirely reasonable to conclude that the biological underpinnings necessary for symbolic thought arose initially as a passive consequence of the extensive developmental reorganization that gave rise to our skeletally distinctive species (Tattersall, 2012). Only later was the new capacity co-opted for the symbolic thought of which they were capable. And, since the biology was already present, the stimulus that carried out that recruitment was necessarily a behavioral one.

So what was that behavioral stimulus? Clearly it was something that was effective on an extremely short timescale; and as I have already suggested, the only plausible candidate is the invention of language: an externalized attribute that, once in place, would have been poised to spread readily throughout a species already possessing the "language-ready brain" (Boeckx \& Benítez-Burraco, 2014) necessary to generate and express it. Significantly, during the period in question, Africa was undergoing periodic environmental stress (deMenocal, 2011), regularly reducing the nascent human population to small and scattered isolates. And one can fairly easily imagine that language in some form emerged within a subset (probably juvenile) of one such isolate. The attachment of names to objects and feelings, and their subsequent mental recombination, might reasonably have initiated a feedback loop between language and thought in the brain: a new dynamic that was exaptive and emergent in both its origin and expression, rather than driven by long-term natural selection. With climatic amelioration and the resulting population expansion and recoalescence, the new cognitive style would then have spread rapidly among members of a species predisposed biologically to adopt it. In support of this scenario, one might not only cite the argument of Bolhuis, Tattersall, Chomsky, and Berwick $(2014,2015)$ and Berwick and Chomsky (2016) that the algorithmic basis for language is relatively simple, making a sudden emergence not only possible but probable, but also empirical observations from 
linguistics (e.g., Kegl, Senghas, \& Coppola, 1999; Senghas, Kita, \& Özyürek, 2005) suggesting that, in the presence of a biologically enabled brain, structured language systems can emerge on a virtually instantaneous timescale. Of course, anything we are able to observe today is doubtless conditioned by the already-linguistic nature of the larger human world; but this example nonetheless emphasizes the potential of the underlying biology.

What makes this scenario additionally attractive is its neat resolution of the long-running paleoanthropological controversy over how the highly derived modern-human upper vocal tract happened to have been on hand precisely when it was needed to express speech. This is because it casts the airway proportions required by articulate speech as a simple byproduct of the retraction of the face beneath the front of the braincase that is the most conspicuous cranial apomorphy of Homo sapiens. And that, in turn, makes the much-disputed positions of the larynx and other structures of the upper vocal tract in various extinct hominids totally irrelevant to the point at which speech and language were acquired by our species. Natural selection (more commonly a force for stability than for change; see Tattersall, 2015) cannot call desirable variations into existence at will; and the structures requisite for speech were necessarily there first, once again in an exaptive context.

Author note I thank Tecumseh Fitch for kindly asking me to contribute these ruminations to this very interesting special issue, and for his and two referees' stimulating comments on earlier drafts.

\section{References}

Bar-Yosef, O., \& Bordes, J.-G. (2010). Who were the makers of the Châtelperronian culture? Journal of Human Evolution, 59, 686593.

Berwick, R. C., \& Chomsky, N. (2016). Why only us: Language and evolution. Cambridge, MA: MIT Press.

Bickerton, D. (1995). Language and human behavior. Seattle, WA: University of Washington Press.

Boeckx, C., \& Benítez-Burraco, A. (2014). The shape of the human language-ready brain. Frontiers in Psychology, 5, 282. doi:10. 3389/fpsyg.2014.00282

Bolhuis, J. J., Tattersall, I., Chomsky, N., \& Berwick, R. (2014). How could language have evolved? PLoS Biology, 12, e101934.

Bolhuis, J. J., Tattersall, I., Chomsky, N., \& Berwick, R. (2015). UG or not to be, that is the question. PLoS Biology, 13, e1002063.

Caron, F., d'Errico, F., Del Moral, P., Santos, F., \& Zilhão, J. (2011). The reality of Neandertal symbolic behavior at the Grotte du Renne, Arcy-sur-Cure, France. PLoS ONE, 6, e21545. doi:10.1371/ journal.pone. 0021545

Chomsky, N. (2000). New horizons in the study of language and mind. Cambridge, UK: Cambridge University Press.
Dediu, D., \& Levinson, S. C. (2013). On the antiquity of language: The reinterpretation of Neandertal linguistic capacities and its consequences. Frontiers in Psychology, 4(397), 1-17. doi:10.3389/ fpsyg.2013.00397

deMenocal, P. (2011). Climate and human evolution. Science, 331, 540542.

Fitch, W. T. (2010). The evolution of language. Cambridge, UK: Cambridge University Press.

Higham, T., Jacob, R., Julien, M., David, F., Basell, L., Wood, R., ... Ramsey, C. (2010). Chronology of the Grotte du Renne (France) and implications for the context of ornaments and human remains within the Chatelperronian. Proceedings of the National Academy of Sciences, 107, 20234-20239.

Hinzen, W. (2012). The philosophical significance of Universal Grammar. Language Sciences, 34, 635-649.

Kegl, J., Senghas, A., \& Coppola, M. (1999). Creation through contact: Sign language emergence and sign language change in Nicaragua. In M. deGraaf (Ed.), Comparative grammatical change: The intersection of language acquisition, creole genesis and diachronic syntax (pp. 179-237). Cambridge, MA: MIT Press.

Klein, R. G. (2009). The human career (3rd ed.). Chicago, IL: Chicago University Press.

Klein, R. G., \& Edgar, B. (2002). The dawn of human culture. New York, NY: Wiley.

Krause, J., Lalueza-Fox, C., Orlando, R., Enard, W., Green, R. E., Burbano, H. A., \& Pääbo, S. (2007). The derived FOXP2 variant of modern humans was shared with Neanderthals. Current Biology, 17, 1908-1912. doi:10.1016/j.cub.2007.10.008

Martínez, I., Rosa, M., Arsuaga, J.-L., Jarabo, P., Quam, R., Lorenzo, C., ... Carbonell, E. (2004). Auditory capacities in Middle Pleistocene humans from the Sierra de Atapuerca in Spain. Proceedings of the National Academy of Sciences, 101, 9976-9981.

Pearce, E., Stringer, C., \& Dunbar, R. I. M. (2013). New insights into differences in brain organization between Neanderthals and anatomically modern humans. Proceedings of the Royal Society B, 280, 20130168. doi:10.1098/rspb.2013.0168

Pinker, S., \& Bloom, P. (1990). Natural language and natural selection. Behavioral and Brain Sciences, 13, 707-727. doi:10.1017/ S0140525X00081061 disc. 727-784.

Plummer, T. (2004). Flaked stones and old bones: Biological and cultural evolution at the dawn of technology. Yearbook of Physical Anthropology, 39, 118-164.

Radovčić, D., Sršen, A. O., Radovčić, J., \& Frayer, D. W. (2015). Evidence for Neandertal jewelry: Modified white-tailed eagle claws at Krapina. PLoS ONE, 10, e0119802. doi:10.1371/journal.pone. 0119802

Rodríguez-Vidal, J., d'Errico, F., Pacheco, F. G., Blasco, R., Rosell, J., Jennings, R. P., ... Finlayson, C. (2014). A rock engraving made by Neanderthals in Gibraltar. Proceedings of the National Academy of Sciences, 111, 13301-13306. doi:10.1073/pnas.1411529111

Senghas, A., Kita, S., \& Özyürek, A. (2005). Children creating core properties of language: Evidence from an emerging sign language in Nicaragua. Science, 305, 1779-1782.

Tattersall, I. (2012). Masters of the planet: The search for our human origins. New York, NY: Palgrave Macmillan.

Tattersall, I. (2015). The strange case of the rickety Cossack, and other cautionary tales from human evolution. New York, NY: Palgrave Macmillan.

Vauclair, J. (1996). Animal cognition: An introduction to modern comparative psychology. Oxford, UK: Oxford University Press. 